\title{
A new species of Poronia from India
}

\section{Hembrom ME ${ }^{1}$, Parihar $\mathrm{A}^{2}$ and Das $\mathrm{K}^{2}$}

\author{
${ }^{1}$ Botanical Survey of India, Central National Herbarium, Howrah 711103, India, email: \\ manojhembrom@yahoomail.com \\ ${ }^{2}$ Botanical Survey of India, Cryptogamy Unit, Howrah 711103, India, email: daskanadbsi@ gmail.com
}

Hembrom ME, Parihar A, Das K, 2013 - A new species of Poronia from India. Current Research in Environmental \& Applied Mycology 3(2), 182-185, doi 10.5943/cream/3/2/1

A new species: Poronia radicata, collected from the historical Aacharya Jagadish Chandra Bose Indian Botanic Garden, Howrah, India is described and illustrated. This species can be characterized by long underground branched rooting base, terminally branched stromata, capitate with an expanded and flattened stromatal disc, absence of paraphyses and apical germ pore (at maturity) and comparatively small sized ascospores with rounded germ pore. Its comparison with the allied species is also mentioned in the present paper.

Key words - Macrofungi - Poronia - taxonomy - Xylariaceae

\section{Article Information}

Received 29 August 2013

Accepted 23 September 2013

Published online 10 October 2013

* Corresponding Author: Kanad Das - e-mail - daskanadbsi@gmail.com

\section{Introduction}

Since long back Xylaria and its allies have been investigated by different mycologists to give their proper taxonomic placement. But always a great debate persists while placing the ascocarp with stipitate stroma (of this group) that ends with capitate to hemispherical or irregular, fertile, variously sculptured head although, these specimens are mainly kept in few closely related genera i.e. Kretzschmaria, Podosordaria, Xylaria and Poronia under the family Xylariaceae (Ahmad 1946, Dennis 1957a \& b, Martin 1967, Rogers 1979). Micromorphological features, like the nature of the spores and germ slits of these genera are not so distinct to separate them from each other. Critical studies undertaken by Ahmad (1946), Dennis (1957a \& b), Martin (1967), Rogers (1979), Pande (2008) helped us to delimit these genera based on their habit and macromorphology. Kretzschmaria can be distinguished from Poronia by its growing habit (caespitose) and the habitat (on wood) as mentioned by Martin (1967). Similarly, Poronia can be separated from both Xylaria and Podosordaria by its stalked stroma which is in the form of capitate to flattened disc (never clavate to filiform or subglobose with erumpent ascocarps) with embedded perithecia (Krug \& Cain 1974, Martin 1967).

Genus Poronia Willd. was erected to accommodate the taxa with "black carbonous perithecia embedded in a white fleshy hemispherical or discoid stroma borne on a long or short stipe" (Ahmed 1946). Later on, Dennis (1957b) included some white flat headed Eastern hemispherical terrestrial Xylaria like taxa with rooting bases (which probably originated from buried wood) under Poronia. This genus (Poronia) can be characterized by upright stipitate fruit bodies; fertile part in the form of capitate to flattened disc on stalked stroma; stromata simple or branched; perithecia embedded in fertile parts, elevations 
evident or lacking; asci stipitate, cylindrical with more or less well-developed apical ring which usually becoming blue with Melzer's reagent; ascospores light to dark brown, asymmetrical, one-celled or unequally twocelled due to presence of hyaline cellular appendage with a short to long conspicuous or inconspicuous germ slit (Llyod 1920; Dennis 1957b, 1978; Martin 1967) .

Aacharya Jagdish Chandra Bose Indian Botanic Garden (AJCBIBG), Howrah is a 227 years old historic botanic garden and abode of several well documented native and exotic flora expanded in 273 acres. Apart from these plants, this garden also harbors a number of macrofungi. During mid-rainy season (JulyAugust, 2013) authors, while undertaking routine survey of AJCBIBG came across an interesting species of Xylariaceae which after thorough macro- and micromorphological studies followed by literature survey reveals as an undescribed taxon and is proposed here as Poronia radicata. Detailed description of this species is given here along with the relevant photographic illustrations.

\section{Materials \& Methods}

Macromorphological/field characterization was made with the fresh fruit bodies. Field photographs of these fruit bodies were taken with the help of Nikon D300s and Olympus C-5060 (wide zoom) camera. Colour codes and terms (mostly) follow Methuen Handbook of Colour (Kornerup and Wanscher, 1978). After recording the macromorphological characters fruit bodies were dried in the sun as well as with a wooden drier.

Micromorphological characters were noted with the aid of a light microscope: Olympus CX 41 based on the dry samples mounted in a mixture of $5 \% \mathrm{KOH}$ and phloxin, $30 \%$ glycerol, lactophenol, cotton blue and Melzer's reagent. Ascospore measurements are recorded based on that of twenty ascospores. Ascospores are measured in side view. Measurements of ascospore-size and length/width ratios (Q) are presented as: minimum-mean-maximum. Herbarium name is after Holmgren et al., 1990.

\section{Taxonomy}

Poronia radicata Hembrom, A. Parihar \& K. Das sp. nov.

MycoBank - MB 805422

Figs. 1-11

Etymology - To recognize the long rooting base of the stromatal stalk.

Fruit bodies (stromata) scattered to gregarious, distinctly marked into fertile head bearing perithecia, supporting stalk holding heads and underground rooting bases, 1.5-5.5 $\mathrm{cm}$ high, overall stromatal exterior glabrous and crusty whereas interior homogenous, waxy in texture, chalky white (A1). Stromatal head, 1-9 mm wide, convex when young gradually capitate with an expanded flattened disc, glabrous, overall (1A2-1B2) when fresh while charcoal black on drying, upper fertile surface rough appearing mammilose (under stereo zoom microscope). Stromatal stalk, $0.5-8 \mathrm{~mm}$ wide, erect to irregularly tortuous, simple to branched, cylindrical to flat, gradually widening towards the head, glabrous, stiriations like decurrent lamellae, yellowish white to orange white (3A2-5A2) powdery mass on outer surface when fresh and young, gradually turning into charcoal black to dull black; texture soft when fresh, waxy and hard when dry, context white; basal underground roots (often more than the half length of fruit bodies) often branched, cylindrical, crusty, solid, gradually thinning towards the tip, $0.2-5$ $\mathrm{mm}$ wide, texture soft when fresh, hard on drying, context white (A1).

Perithecia globose to slightly elongate, 600-800 × 450-600 $\mu \mathrm{m}$, papillate, papillae $130-170 \mu \mathrm{m}$ long, most of the part embedded in white and waxy flesh, each perithecia are separated from the each other by up to $50 \mu \mathrm{m}$. Asci 8-spored, 62-68 $\times 5-7 \mu \mathrm{m}$, arranged in a uniseriate manner, cylindrical, stipitate, spore bearing part 35-41 $\mu \mathrm{m}$ long, cube shaped apical ring up to $1.5 \mu \mathrm{m}$, which turns blue in Melzer's reagent and found only in young specimens. Paraphyses $80-150 \times 3-5 \mu \mathrm{m}$, hyaline, septate, many, remain among the asci and visible well in young specimens. Ascospores 5-6.96-9 × 2.5-3.15-4 $\mu \mathrm{m}, \mathrm{Q}=$ 1.33-2.24-3, hyaline to dark olive brown, fusiform, (sometimes concave in one side). 

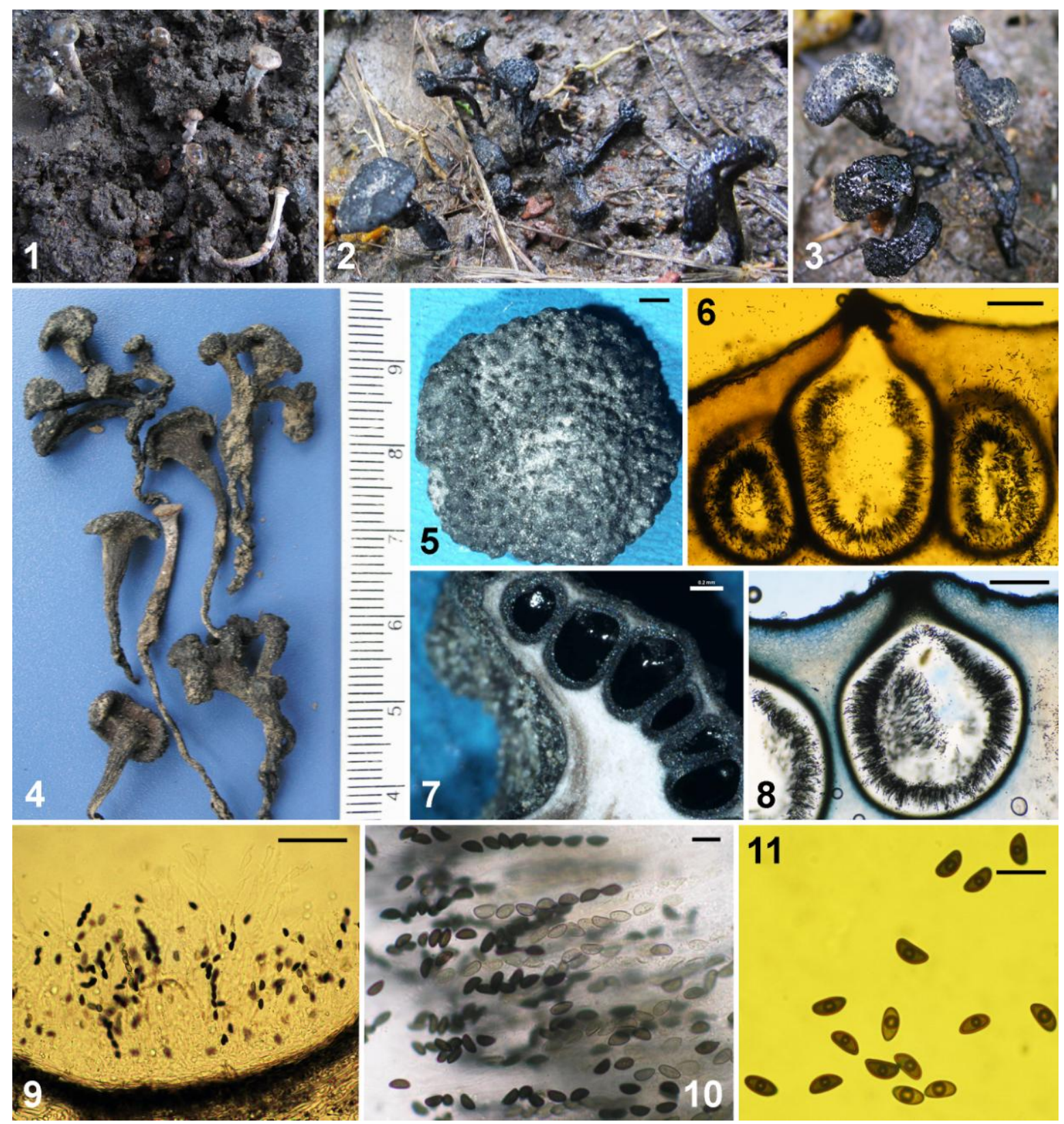

Figs 1-11 - Poronia radicata Hembrom, A. Parihar \& K. Das (KMA 13-023). 1-3 Young and mature fruit bodies on their habitat. 4 Fruit bodies showing capitate stromatal head and rooting stromatal base. 5 Top view of stromatal head. 6, 8 Papillate perithecia. 7 Longitudinal section through stromatal head showing the arrangement of perithecia. 9 Spores and paraphysis inside the perithecia of young fruit body. 10-11 Ascospores. Scale bars: $\mathbf{5}=1 \mathrm{~mm} ; \mathbf{6}, \mathbf{8}, \mathbf{9}=50 \mu \mathrm{m} ; \mathbf{7}=0.2$ $\mathrm{mm} ; \mathbf{1 0}, \mathbf{1 1}=10 \mu \mathrm{m}$.

Specimens examined - Type: India, West Bengal, Howrah, Shibpur, AJCBIBG, alt. 12m, N 22 33'39.1" E 88 18'03.7", on ground, under hedge of Putranjiva roxburghii Wall., 15 July 2013, K. Das, M.E. Hembrom \& A. Parihar, KMA 13-023, CAL 1140 (holotype).

Notes - Xylaria like erect habit of fruit bodies, scattered to gregarious and terrestrial growing pattern, stalked stroma bearing fertile disc which is capitate to expanded or flattened, place the present taxon under the genus Poronia. Considering most of the macro- and micromorphology, Poronia radicata appears to be quite close to Poronia pileiformis (Berk.) Fr. but, the latter one can only be separated by its distinct bulbous (never rooting or tortuous or branched) base and the coprophilous habitat (Rawla \& Narula 1983). Feature like the stromata with long rooting base of the present species well resembles Xylaria kurziana Curr. 
(also reported from AJCBIBG), (Currey 1874, Ahmad 1946) but X. kurziana can be separated by its distinguishingly larger spores: $12.5-16.5$ $\times 6-7.5 \mu \mathrm{m}$ (Ahmad 1946).

Moreover, the combination of features like, long underground branched rooting base (more than half of the length of the entire fruiting bodies), upright branched stipe and/terminally branched stromata, absence of paraphyses and apical germ pore in the mature specimens and hyaline to dark olive brown comparatively small sized spores with rounded germ pore, undoubtedly, place the present taxon as a distinct species. Furthermore, Poronia radicata are found on ground and under hedge of Putranjiva roxburghii Wall.

\section{Acknowledgements}

The authors are grateful to the Director, Botanical Survey of India, Kolkata for providing all the facilities during the study of this material. Thanks are due to Dr. Md. N. Aziz (BSI, Cryptogamy) and Dr. A. Paramanik (BSI, CBL) for helping the authors in many ways.

\section{References}

Ahmad S. 1946 - The genus Poronia in India. Llyodia 9(2), 139-143.

Bilgrami KS, Jamaluddin S, Rizwi MA. 1981 Fungi of India List and References. Today and Tomorrow's Printers \& Publishers, New Delhi.798pp.

Curry F. 1874 - On a collection made by Mr. Sulpiz Kurz, Curator of the Botanic
Garden, Culcutta. Trans. Linn. Soc. Ser. 2 Bot. 1, 119-131.

Dennis RWG. 1957a - Some Xylarias of Tropical America. Kew Bulletin 1, 401-444

Dennis RWG. $1957 b$ - Further notes on tropical American Xylariaceae. Kew Bulletin 2, 297-333.

Dennis RWG. 1978 - British Ascomycetes. Lubrecht \& Cramer Ltd.

Holmgren PK, Holmgren NH, Barnett LC. 1990 - Index Herbariorum. Part I: Herbaria of the world, $86^{\text {th }}$ ed. Bronx: New York Botanical Garden, USA.

Kornerup A, Wanscher JH. 1978 - Methuen Handbook of Colour. Third Edition. UK, London, Eyre Methuen Ltd. Reprint.

Krug JC, Cain RF. 1974 - A preliminary treatment of the genus Podosordaria. Canadian Journal of Botany 52, 589605.

Llyod GC. 1920 - The genus Poronia. Mycological Notes 6, 937-941.

Martin P. 1967 - Studies in the Xylariaceae: I. New and old concepts. South African Journal of Botany. 36, 205-240.

Pande A. 2008 - Ascomycetes of Peninsular India. Scientific Publishers, Jodhpur.

Rawla GS, Narula AM. 1983 - Poronia pileiformis (Berk.) Fr. a new record from India. Current Science 52, 990p.

Rogers JD. 1979 - The Xylariaceae: Systematic, Biological and Evolutionary aspects. Mycologia 71(1), 1-42. 